Review

\title{
Vitamin D and Colorectal, Breast, and Prostate Cancers: A Review of the Epidemiological Evidence
}

\author{
Elizabeth T. Jacobs ${ }^{\bowtie}$, Lindsay N. Kohler, Andrew G. Kunihiro, Peter W. Jurutka \\ University of Arizona Cancer Center, Tucson, Arizona (ETJ); Mel and Enid Zuckerman College of Public Health, University of Arizona, Tucson, Arizona (ETJ, \\ LNK); Department of Nutritional Sciences, University of Arizona, Tucson, Arizona (ETJ, AGK); School of Mathematical and Natural Sciences, Arizona State \\ University, Phoenix, Arizona (PWJ); Department of Basic Medical Sciences, The University of Arizona, College of Medicine, Phoenix, AZ (PWJ). \\ $\triangle$ Corresponding author: Elizabeth T. Jacobs, University of Arizona Cancer Center, 1515 N. Campbell Ave, Tucson, AZ 85724-5024. Phone: 520-626-0341, Fax:
} 520-626-9275, Email: jacobse@email.arizona.edu

( ) Ivyspring International Publisher. Reproduction is permitted for personal, noncommercial use, provided that the article is in whole, unmodified, and properly cited. See http://ivyspring.com/terms for terms and conditions.

Received: 2015.07.30; Accepted: 2015.12.03; Published: 2016.01.05

\begin{abstract}
Over the past two decades, the question of whether vitamin $D$ has a role in cancer incidence, progression, and mortality has been studied in detail. Colorectal, breast, and prostate cancers have been a particular area of focus; together, these three malignancies account for approximately $35 \%$ of cancer cases and $20 \%$ of cancer deaths in the United States, and as such are a major public health concern. Herein, we review and synthesize the epidemiological research regarding vitamin $D$, as measured by the biomarker 25-hydroxycholecalciferol $[25(\mathrm{OH}) \mathrm{D}]$, and the incidence, progression, and mortality of these cancers. Overall, the results of observational studies of the relationship between $25(\mathrm{OH}) \mathrm{D}$ and colorectal cancer have revealed a consistent inverse association for incidence and mortality; while for breast cancer, results have generally demonstrated a relationship between higher $25(\mathrm{OH}) \mathrm{D}$ and lower risk for progression and mortality. In contrast, randomized, double-blind clinical trials conducted to date have generally failed to support these findings. For prostate cancer, there is no convincing evidence of an association between $25(\mathrm{OH}) \mathrm{D}$ and incidence, and inconsistent data for progression and mortality, though results of one open label clinical trial suggest that supplementation with $4000 \mathrm{IU} / \mathrm{d}$ of vitamin $\mathrm{D}_{3}$ may inhibit progression of the disease. Nonetheless, until the results of additional ongoing randomized, double-blind clinical trials are reported, it will be difficult to ascertain if vitamin $D$ itself is related to a reduction in risk for some cancer endpoints, or whether high concentrations of the vitamin D biomarker $25(\mathrm{OH}) \mathrm{D}$ may instead serve as a marker for an overall beneficial risk factor profile.
\end{abstract}

Key words: Vitamin D, colorectal cancer, breast cancer, prostate cancer, 25(OH)D

\section{Introduction}

Vitamin D has been the subject of intense scrutiny in relation to various cancer endpoints, with particular focus on the incidence and mortality of colorectal, breast, and prostate cancers. Together, these three malignancies account for approximately $35 \%$ of cancer cases and $20 \%$ of cancer deaths in the United States ${ }^{1}$. After more than two decades of comprehensive efforts to elucidate the role of vitamin D in cancer, we now have the opportunity to synthesize the $\mathrm{cu}$ mulative knowledge about this subject in order to evaluate whether vitamin $\mathrm{D}$ is related either positively or negatively to cancer incidence, prognosis, and/or survival in relation to colorectal, breast, and prostate cancers.

Conducting and interpreting epidemiological studies of vitamin D and health outcomes can be complex due to inherent nature of the biomarkers employed to evaluate vitamin D status. First, dietary studies of vitamin D are somewhat limited because of the major contribution of endogenous synthesis after UV exposure to circulating concentrations of the vitamin $\mathrm{D}$ metabolite 25-hydroxycholecalciferol [25(OH)D]. In part because it captures both dietary intake and endogenous synthesis of vitamin $\mathrm{D}$, total 
circulating concentration of $25(\mathrm{OH}) \mathrm{D}$ is the biomarker that is most frequently used in epidemiological investigations; for this reason, the present review will include only those investigations that employed $25(\mathrm{OH}) \mathrm{D}$ as a marker of vitamin D status. In contrast, the active vitamin $\mathrm{D}$ metabolite 1,25-dihydroxycholecalciferol $\left[1,25(\mathrm{OH})_{2} \mathrm{D}\right]$, which is produced after hydroxylation of $25(\mathrm{OH}) \mathrm{D}$, is the primary metabolite employed for in vitro experiments, which have provided extensive evidence of several potential mechanisms of action for vitamin D in carcinogenesis. There are general limitations to the use of either biomarker. In the case of $1,25(\mathrm{OH})_{2} \mathrm{D}$, it is subject to tight homeostatic regulation and as such does not vary as greatly in human populations as does $25(\mathrm{OH}) \mathrm{D}$. On the other hand, circulating $25(\mathrm{OH}) \mathrm{D}$ is influenced by an array of individual characteristics that are themselves related to cancer risk either directly or indirectly, including diet, body size, physical activity, sun exposure, and skin pigmentation. We will revisit the implications of this epidemiological challenge later in the review in the context of the work conducted to date regarding colorectal, breast, and prostate cancer incidence and mortality.

\section{Colorectal Cancer}

An estimated 93,090 new cases of colon cancer and 39,610 cases of rectal cancer are anticipated in 2015․ Among men and women combined, colorectal malignancies are the second most common cause of cancer mortality in the United States, with approximately 50,000 deaths each year ${ }^{2}$. The primary precursor lesions for colorectal cancer are adenomas ${ }^{3}$, and a meta-analysis of the presence of adenomas among U.S. adults has estimated a range from $22 \%$ to over $50 \%$, with a pooled prevalence of approximately $30 \% 4$. Among individuals in whom an adenoma has been detected and removed, $10-15 \%$ per year will go on to develop another, recurrent, adenoma ${ }^{5}$. Thus, examining the role of vitamin D in colorectal adenoma incidence and recurrence provides important information regarding its potential for preventing colorectal malignancies during the first steps in the carcinogenesis pathway.

To date, meta-analyses of the association between serum 25(OH)D and colorectal adenoma have consistently demonstrated a statistically significant inverse relationship for incidence, but not recurrence, though data for the latter outcome are comparatively sparse $^{6,7}$. Since the results of these meta-analyses were reported, a third study of adenoma recurrence was published, which again showed no statistically significant association between 25(OH)D and odds of adenoma recurrence ${ }^{8}$. Underlying mechanisms for the observed differences in the association for $25(\mathrm{OH}) \mathrm{D}$ by incident vs. recurrent adenomas are currently only speculative. Differences in methylation patterns during adenoma growth and development ${ }^{9}$ and variation in expression of key vitamin D pathway enzymes such as CYP24A1 in adenoma tissue during different stages of adenoma development ${ }^{10,11}$ are two potential pathways through which vitamin D may exert differential effects on adenoma incidence vs. recurrence. It is also possible that individuals included in studies of recurrent lesions represent a population of "polyp formers" for whom the risk factor profile is different, and/or for whom the carcinogenic pathway is not affected by vitamin $\mathrm{D}$. Taken together, these observational studies indicate that vitamin D may have a role in reducing the risk of incident colorectal adenomas, but after removal of these lesions, there is no evidence that it will prevent the formation of another. Results of the Vitamin D/Calcium Polyp Prevention Study12, a large, double-blind, randomized clinical trial of vitamin $\mathrm{D}$ and calcium supplementation for the prevention of colorectal adenoma recurrence, are pending and are expected to provide more definitive data. We will next move forward in the carcinogenesis pathway to consider the potential role of vitamin D in the incidence of colorectal cancer.

To date, several meta-analyses of blood $25(\mathrm{OH}) \mathrm{D}$ concentrations and colorectal cancer incidence have been conducted, and all have shown a statistically significant inverse association ${ }^{13-16}$. In contrast to the results for breast cancer, as discussed further below, the majority of studies conducted to assess the relationship between $25(\mathrm{OH}) \mathrm{D}$ and colorectal cancer incidence are prospective investigations that have reported a significantly reduced risk for colorectal cancer with higher $25(\mathrm{OH}) \mathrm{D}$ concentrations. When comparing the highest vs. lowest categories of $25(\mathrm{OH}) \mathrm{D}$ levels, consistent estimates of 0.67 $(0.54-0.80)^{13}$ and $0.66(0.54-0.81)^{16}$ were yielded for colorectal cancer risk. In contrast, for analogous analyses employing the endpoint of colorectal adenoma, the magnitude of effect has tended to be somewhat weaker and less consistent ${ }^{6,7}$. Further, as described above, 25(OH)D levels have generally not been found to prevent recurrent lesions. As hypothesized by Yin et al. ${ }^{6}$, these findings support the concept that vitamin D may not inhibit the formation of new adenomas, but rather that it may have a role in inhibiting growth of existing lesions and/or progression through the carcinogenesis pathway.

When examining observational studies in greater detail, further information about potential sub-site and sex-specific effects emerges. Some studies have indicated that the association with $25(\mathrm{OH}) \mathrm{D}$ is stronger in rectal cancers than in colon cancers ${ }^{17,18}$; however, others have reported a potentially stronger 
effect for colon cancers than rectal or colorectal cancers $^{19,20}$. In one of the two studies where a stronger effect for rectal cancer was observed, women were included in the study population ${ }^{18}$. In the two studies for which a stronger association with colon cancer was demonstrated, both included men and women ${ }^{19,20}$. The paucity of sub-site specific data for each sex separately, as well as the often-limited number of cases available for analysis by sub-site, precludes drawing firm conclusions about whether vitamin $\mathrm{D}$ may have differential effects in men vs. women with regard to colorectal cancer incidence. However, it is worth noting that in study populations that included only women, a significant inverse association between $25(\mathrm{OH}) \mathrm{D}$ and colorectal cancer overall was observed ${ }^{21,22}$; while for studies including only men, the results were either null, showed a stronger association for rectal rather than colon cancer, or demonstrated a direct relationship between $25(\mathrm{OH}) \mathrm{D}$ and colorectal cancer whereby higher concentrations were related to an increased risk for colorectal cancer ${ }^{17,23,24}$. The results from observational studies suggest the possibility that women may experience a greater benefit from higher $25(\mathrm{OH}) \mathrm{D}$ levels in relation to the development of colorectal cancer overall; however, despite intensive research, firm conclusions cannot be drawn for a sex-specific effect. In summary, while there is a consistent association between $25(\mathrm{OH}) \mathrm{D}$ and colorectal cancer incidence reported in observational epidemiological studies, colorectal subsite- or sex-specific effects cannot be ascertained from the current literature.

Randomized, controlled clinical trials provide the best evidence for whether vitamin $\mathrm{D}$ might reduce the risk of colorectal cancer, and to date, only two have been published with data specific to colorectal cancer ${ }^{22,25}$. The Women's Health Initiative (WHI) randomized women to $400 \mathrm{IU}$ vitamin $\mathrm{D}_{3}$ and $1000 \mathrm{mg}$ of calcium vs. placebo. No differences in risk for colorectal cancer by treatment group were observed, although some limitations of the trial were noted, including the relatively healthy study population, the timing of the intervention, and the comparatively short follow-up time ${ }^{22}$. In addition, it has been suggested that the dose of vitamin D used in WHI was too low to elicit protective effects ${ }^{26}$. Another clinical trial conducted in the United Kingdom randomized men and women to receive 100,000 IU/d of vitamin $\mathrm{D}_{3}$ every four months for five years ${ }^{25}$. No reduction in risk of either colorectal cancer incidence or mortality was observed ${ }^{25}$. Thus, while association studies of $25(\mathrm{OH}) \mathrm{D}$ and colorectal cancer incidence indicate a potential risk reduction with higher concentrations of this vitamin D biomarker, evidence from randomized clinical trials does not support this finding. Results from the ongoing Vitamin D and Omega-3 Trial (VITAL) trial, in which participants are supplemented with $2000 \mathrm{IU} / \mathrm{d}$ of vitamin $\mathrm{D}_{3}$ with and without an omega-3 fatty acid supplement to ascertain whether the intervention can prevent the development of cancer or cardiovascular disease ${ }^{27}$, will likely provide more definitive evidence regarding whether vitamin $\mathrm{D}$ is a viable strategy for colorectal cancer prevention. Next, we will explore the studies of $25(\mathrm{OH}) \mathrm{D}$ and colorectal cancer progression and survival.

Two investigations have assessed the association between $25(\mathrm{OH}) \mathrm{D}$ concentrations and colorectal cancer progression specifically. Mezawa et al. ${ }^{28}$ measured blood levels of $25(\mathrm{OH}) \mathrm{D}$ in Stage I-IV patients at the time of surgery for this malignancy and found that although $25(\mathrm{OH}) \mathrm{D}$ levels were significantly directly related to overall survival, they were not associated with disease-free survival. In another study conducted among Stage IV colorectal cancer patients undergoing chemotherapy, concentrations of $25(\mathrm{OH}) \mathrm{D}$ were not significantly associated with time to progression of disease ${ }^{29}$. Therefore, to date, there is no evidence that vitamin $\mathrm{D}$ is associated with inhibiting colorectal cancer progression per se, although it may have an impact on cancer-related mortality.

Several prospective epidemiological investigations have been completed that were designed to ascertain if there is a relationship between $25(\mathrm{OH}) \mathrm{D}$ and deaths associated with colorectal cancer and/or all-cause mortality $28-35$, with equivocal results. Five studies have reported a significant inverse association between 25(OH)D and either colorectal cancer-specific or all-cause mortality 28,31,33-35, with three others observing null relationships ${ }^{29,30,32}$. The reasons for the differential results between these studies are unclear; there did not appear to be general marked variation in the stage at diagnosis, sex, or study design (pre- vs. post-diagnostic samples) between the studies that showed an association as compared to those that did not. Three of the five studies demonstrating a statistically significant outcome were conducted outside of the United States; one from the Study of Colorectal Cancer in Scotland (SOCCS) ${ }^{33}$; one from the European Prospective Investigation into Cancer and Nutrition (EPIC), which included participants from Denmark, France, Germany, Greece, Italy, the Netherlands, Norway, Spain, Sweden, and United Kingdom $^{31}$; and one from Japan ${ }^{28}$. However, given the variation in latitude and diet between the participant counties, it is difficult to draw firm conclusions regarding the potential relationship between $25(\mathrm{OH}) \mathrm{D}$ and survival. For this, we must consider several meta-analyses ${ }^{36-38}$ that have recently been completed. Each has reported that higher concentrations of $25(\mathrm{OH}) \mathrm{D}$ were significantly inversely related to re- 
duced risk for cancer-specific and/or overall mortality among patients with colorectal cancer. Based on these findings, there is consistent evidence of an inverse association between $25(\mathrm{OH}) \mathrm{D}$ and colorectal cancer-related mortality. However, as discussed further below, caution is warranted in drawing conclusions about causality from these studies.

\section{Breast Cancer}

It has been estimated that there will be 231,840 new cases of female breast cancer and 40,290 deaths from this disease in $2015^{1}$. Unlike with colorectal carcinogenesis, there are limited data regarding vitamin $\mathrm{D}$ and breast cancer precursor lesions. In one study among participants in the WHI, Rohan et al. found no reduction in risk for benign proliferative breast disease, a condition associated with increased risk for breast cancer (HR=0.99, 95\% CI=0.86-1.13), among women receiving calcium and vitamin $\mathrm{D}^{39}$. In contrast to studies of breast precursor lesions, there are a number of reports regarding vitamin $\mathrm{D}$ and breast cancer incidence, progression, and mortality.

Four thorough meta-analyses that included both case-control and prospective studies of the relationship between circulating concentrations of $25(\mathrm{OH}) \mathrm{D}$ and risk for breast cancer have been published to date $^{14,40-42}$. When presenting the point estimates for both types of epidemiological studies combined, results have generally shown a statistically significant inverse relationship between $25(\mathrm{OH}) \mathrm{D}$ and breast cancer ${ }^{14,40,41}$. However, several groups that have examined the results by study design reported a marked and important difference in results depending on the type of epidemiological study ${ }^{14,40,43}$. Specifically, case-control studies have generally shown a statistically significant reduction in risk for breast cancer associated with higher circulating concentrations of $25(\mathrm{OH}) \mathrm{D}$, with reported summary ORs $(95 \% \mathrm{CIs})$ from separate meta-analyses of $0.59(0.48,0.73)^{40}$ and $0.83(0.79,0.87)^{14}$ for the highest vs. lowest category of $25(\mathrm{OH}) \mathrm{D}$ levels. In contrast, prospective studies have shown no significant relationship between 25(OH)D and breast cancer incidence, with summary statistics of $0.92(0.82,1.04)^{40}$ and $0.97(0.92,1.03)^{14}$. Further, since the publication of these meta-analyses, numerous additional reports have been published ${ }^{41,42,44-57}$. These studies have maintained a striking fidelity with the general pattern of case-control studies reporting a significant association and prospective findings being null. This distinction is critical to the interpretation of the overall body of literature related to vitamin D and cancer.

As mentioned previously, concentrations of $25(\mathrm{OH}) \mathrm{D}$ are influenced not only by dietary intake, but also by important risk factors for cancer such as body size and sun exposure, both of which are associated with a third cancer-related variable, physical activity. It has been clearly demonstrated that concentrations of $25(\mathrm{OH}) \mathrm{D}$ are lower among those with higher body mass index and lower physical activity levels, which themselves are documented outcomes after a diagnosis of breast cancer ${ }^{58,59}$. We and others ${ }^{14,59,60}$ have suggested that case-control studies, with blood from cases being drawn after diagnosis, have substantial limitations due to the potential influence of a breast cancer diagnosis on $25(\mathrm{OH}) \mathrm{D}$ concentrations, rather than the converse. Further, the most recent meta-analysis of all studies of $25(\mathrm{OH}) \mathrm{D}$ and breast cancer, which included the majority of work through 2013, reported a null association for measured $25(\mathrm{OH}) \mathrm{D}$ and incidence, with a pooled OR (95\% CI) of 0.92 (95\% CI: 0.83-1.02) for the highest category of $25(\mathrm{OH}) \mathrm{D}$ compared to the lowest ${ }^{42}$, regardless of study design. To date, the only large randomized clinical trial that has been completed is the WHI, which demonstrated no reduction in risk for breast cancer among women receiving $400 \mathrm{IU}$ vitamin $\mathrm{D}_{3}$ and $1000 \mathrm{mg}$ of calcium vs. placebo ${ }^{61}$. In total, the evidence does not support a role for vitamin D in the prevention of breast cancer incidence. The literature regarding vitamin $\mathrm{D}$ and breast cancer prognosis and survival will next be considered.

Two meta-analyses of the association between vitamin $\mathrm{D}$ and breast cancer survival have recently been published, and both reported that higher concentrations of $25(\mathrm{OH}) \mathrm{D}$ were related to better survival among women diagnosed with breast cancer ${ }^{42,62}$. These findings clearly reflect the body of literature on this subject, for which the majority of studies have reported a statistically significant relationship between higher blood 25(OH)D levels and less-advanced cancers or improved prognosis, including reduced risk for recurrence and increased breast cancer survival or all-cause survival ${ }^{32,63-66}$. In addition, in a retrospective review of patients by Zeichner et al ${ }^{67}$, HER2 ${ }^{+}$patients who were undergoing chemotherapy with trastuzumab and who also received vitamin D supplements experienced statistically significantly improved disease-free survival as compared to those on the same therapy who did not take a vitamin D supplement. In this study, the mean dose of vitamin D received by patients was 10,472 IU/week, or $<1500 \mathrm{IU} / \mathrm{d}^{67}$. Taken together, the results for prognosis and survival generally provide a more consistent picture than for vitamin D and breast cancer incidence. These were well-conducted observational studies that generally controlled for factors that may confound the relationship between $25(\mathrm{OH}) \mathrm{D}$ and breast cancer survival such as body size, physical activity, and cancer stage at diagnosis. Nonetheless the 
potential for residual confounding remains, particularly in light of the differential findings for vitamin D and breast cancer incidence by study design, and can be resolved only through the conduct of a randomized, double-blind, placebo-controlled trial of vitamin D supplementation among breast cancer patients.

\section{Prostate Cancer}

With 220,800 cases and 27,540 deaths anticipated in 2015, prostate cancer remains a major public health challenge ${ }^{1}$. As mentioned above, increased skin pigmentation is associated with substantially reduced circulating concentrations of $25(\mathrm{OH}) \mathrm{D}$, and as such, African-Americans have consistently been shown to have significantly lower $25(\mathrm{OH}) \mathrm{D}$ levels than any other group in the U.S.68,69. In part because African-American men also suffer from the highest incidence and mortality rates from prostate cancer ${ }^{1}$, it was originally hypothesized that both this health disparity and overall risk for prostate cancer in general might be at least partly attributable to vitamin D insufficiency $^{70}$.

As with breast cancer, there are limited data regarding vitamin $\mathrm{D}$ and precursor lesions for prostate cancer. Gee et al. ${ }^{71}$ administered either placebo $(n=15)$ or $10 \mu \mathrm{g} / \mathrm{d}$ of $1 \mathrm{a}$-hydroxyvitamin $\mathrm{D}_{2}(\mathrm{n}=16)$, a vitamin $\mathrm{D}$ analogue with low calcemic activity, to participants with high-grade prostatic intraepithelial neoplasia (HGPIN) prior to prostatectomy. After 28 days, no significant differences were observed between the two treatment groups for Gleason grade, proliferation, apoptosis, or angiogenesis, though a statistically significant difference was detected for plasma TGF- $\beta 2$ levels, with lower levels observed among those who received 1a-hydroxyvitamin $\mathrm{D}_{2}{ }^{71}$.

Regarding prostate cancer, approximately 30 studies of the association between $25(\mathrm{OH}) \mathrm{D}$ and prostate cancer incidence have been conducted $24,53,55,72-95$. Of these, only two have reported a clear and statistically significant inverse relationship for overall risk of prostate cancer ${ }^{75,80}$; while an additional five studies demonstrated an increased risk for prostate cancer associated with higher concentrations of $25(\mathrm{OH}) \mathrm{D}^{24,76,83,88,92}$. The remainder of the published reports are null for the endpoint of overall prostate cancer incidence; however, a meta-analysis published in 2014 of 21 studies reported a statistically significant finding that higher $25(\mathrm{OH}) \mathrm{D}$ concentrations were related to a higher risk for developing prostate cancer ${ }^{96}$. Taken together, epidemiological association studies have provided no convincing evidence that higher concentrations of $25(\mathrm{OH}) \mathrm{D}$ might reduce the risk of developing prostate cancer. In fact, the evidence indicating that higher $25(\mathrm{OH}) \mathrm{D}$ levels may be directly associated with an increased risk of prostate cancer is stronger than for any putative protective relationship. Next, whether vitamin D might have an impact on progression of prostate cancer or prostate cancer mortality will be explored.

To date, several studies have reported a significant inverse association between $25(\mathrm{OH}) \mathrm{D}$ and more advanced prostate cancers $89,91,94$, which might suggest that vitamin $\mathrm{D}$ has an inhibitory effect on prostate cancer progression and/or that it may be critical in the carcinogenesis pathway from which clinically relevant, but not less aggressive, cancers arise ${ }^{97}$. However, other investigations have failed to show such a relationship $82,85,95$, or have even demonstrated a significantly increased risk for aggressive prostate cancer with higher levels of $25(\mathrm{OH}) \mathrm{D}^{83,84,88}$. Thus far only one clinical trial has been completed which provides evidence of a role for vitamin $\mathrm{D}$ in prostate cancer progression. In this open-label study, a total of 44 men with low-risk prostate cancer completed a trial in which they were administered $4000 \mathrm{IU} / \mathrm{d}$ of vita$\min \mathrm{D}_{3}$ for one year in order to determine whether the supplement could inhibit cancer progression or reduce prostate-specific antigen levels as compared to 19 historical controls ${ }^{98}$. No marked differences in PSA level were observed with vitamin D supplementation from baseline to-follow up as compared to placebo. However, while $63 \%$ of the historical controls exhibited progression as defined by an increase in the number of positive biopsy cores or in Gleason score, only $34 \%$ of those supplemented with vitamin $D_{3}$ progressed ${ }^{98}$. These findings therefore indicate that some benefit may be attained from vitamin D supplementation in men with prostate cancer, but a larger randomized, double-blind clinical trial would be required to confirm these results.

Regarding mortality, studies conducted to date of $25(\mathrm{OH}) \mathrm{D}$ and prostate cancer mortality have been equivocal, with some studies showing a significant inverse association ${ }^{91,99,100}$ and others being null $88,95,101,102$. Therefore, there is no convincing evidence that vitamin $\mathrm{D}$ will prevent prostate cancer, some evidence that it may prevent progression of early-stage disease, and inconsistent findings for mortality.

Overall, association studies of circulating concentrations of $25(\mathrm{OH}) \mathrm{D}$ and colorectal, breast, and prostate cancer incidence, progression, or mortality have yielded a wide range of results of varying consistency. As shown in Figure 1, the evidence is strongest for an association between $25(\mathrm{OH}) \mathrm{D}$ and colorectal adenoma incidence, colorectal cancer incidence and mortality, and breast cancer progression and/or mortality. However, data from randomized, controlled clinical trials completed to date generally provide no support for the findings of the association 
studies. This highlights some major challenges for the field, including several integral challenges regarding the employment of $25(\mathrm{OH}) \mathrm{D}$ as a biomarker for vitamin $\mathrm{D}$, as discussed below.

The first question raised by disparate findings of association studies as compared to clinical trials is whether circulating concentrations of $25(\mathrm{OH}) \mathrm{D}$ act as an appropriate biomarker for vitamin $\mathrm{D}$. It is possible that in addition to serving as a biochemical marker for vitamin $\mathrm{D}$ intake and endogenous synthesis, $25(\mathrm{OH}) \mathrm{D}$ captures other important information about an individual's risk factor profile that either directly or indirectly is itself associated with health outcomes ${ }^{59}$. As mentioned previously, such characteristics that have been well-documented to be related to $25(\mathrm{OH}) \mathrm{D}$ levels include body size, physical activity, genetic background, and skin pigmentation ${ }^{59}$. For example, an individual with a lower BMI and higher physical activity levels is more likely to have higher $25(\mathrm{OH}) \mathrm{D}$ concentrations than a person with a high BMI who exercises less frequently. However, because both a smaller body size and greater physical activity are both related to lower cancer risk, it is difficult to separate the effects of these characteristics from those that may be attributed to $25(\mathrm{OH}) \mathrm{D}$ levels. As such, we previously hypothesized that $25(\mathrm{OH}) \mathrm{D}$ may act as a biomarker for a healthier lifestyle itself that may be related to a lower risk for cancer ${ }^{59}$. Although the majority of the studies reviewed herein have statistically controlled for at least some of these variables, the potential for residual confounding remains a major challenge for epidemiological studies ${ }^{103}$.

The second major question relates to the translation of laboratory experiments of vitamin D and cancer to human populations. Specifically, laboratory work has convincingly shown that $1,25(\mathrm{OH})_{2}$ D elicits potent anti-carcinogenic effects including inhibition of cellular proliferation and growth and induction of differentiation in cancer cells $104,105,106,107$. However, as mentioned above, historically $1,25(\mathrm{OH})_{2} \mathrm{D}$ was rarely measured in large epidemiological studies due to both technical measurement challenges and because it is subject to rigid homeostatic control and thus exhibits less variation in human populations ${ }^{108}$. Individual characteristics that are associated with circulating concentrations of $25(\mathrm{OH}) \mathrm{D}$ do not appear to have the same relationship with levels of $1,25(\mathrm{OH})_{2} \mathrm{D}^{109}$; however, recent work has demonstrated that supplementation with $4000 \mathrm{IU} / \mathrm{d}$ of vitamin $\mathrm{D}_{3}$ significantly increases $1,25(\mathrm{OH})_{2} \mathrm{D}$ concentrations in the blood ${ }^{98}$, suggesting that these levels may be more responsive to intake than was perhaps previously thought. Nonetheless, local synthesis of $1,25(\mathrm{OH})_{2} \mathrm{D}$ at the cellular level has been established to be of key importance in any anti-carcinogenic effect of the hormone ${ }^{110}$. Colon carcinoma (Caco-2) cells possess 25-hydroxyvitamin $\quad \mathrm{D}_{3} \quad$ 1-alpha hydroxylase (CYP27B1) activity ${ }^{111}$, and this enzyme is responsible for the hydroxylation of $25(\mathrm{OH}) \mathrm{D}$ to form $1,25(\mathrm{OH})_{2} \mathrm{D}$. CYP27B1 expression is increased in early colon tumors, but is partially or fully inhibited as colon cells become undifferentiated ${ }^{112}$; while the $1,25(\mathrm{OH})_{2} \mathrm{D}$ catabolizing enzyme (CYP24A1) is increased in colon cancer cells ${ }^{111}$, suggesting that the amount of cellular $1,25(\mathrm{OH})_{2} \mathrm{D}$ available as cancer progresses is substantially suppressed. In addition, we have shown that genetic variants in these enzymes markedly affect the cellular activity of CYP27B1 and CYP24A1113. As such, even if $1,25(\mathrm{OH})_{2} \mathrm{D}$ may potentially provide information about systemic availability of the hormone, it is unlikely to capture data regarding the localized, cellular synthesis of $1,25(\mathrm{OH})_{2} \mathrm{D}$.

Another potential challenge to studying the effects of vitamin D in epidemiological work is related to interactions with calcium, which itself has been linked to cancer outcomes ${ }^{114,115}$. The vitamin D metabolite $1,25(\mathrm{OH})_{2} \mathrm{D}$ has a critical role in calcium homeostasis 116 ; a decrease in calcium results in secretion of parathyroid hormone, which in turn results in increased production of $1,25(\mathrm{OH})_{2} \mathrm{D}^{117}$. Therefore, greater intake of calcium in the diet may in fact suppress the production of $1,25(\mathrm{OH})_{2} \mathrm{D}$ at the cellular level, which would in turn attenuate any chemopreventive effects of this metabolite.

\begin{tabular}{|c|c|c|c|c|}
\hline \multicolumn{2}{|c|}{$\begin{array}{c}\text { Pre-cancerous } \\
\text { lesions }\end{array}$} & Incidence & Progression & Mortality \\
\hline Incident & Recurrent & Colorectal Cancer & Colorectal Cancer & Colorectal Cancer \\
\hline & & Breast Cancer & Breast & Cancer \\
\hline & & Prostate Cancer & Prostat & Cancer \\
\hline
\end{tabular}

Figure 1. Summary of findings from observational epidemiological studies of $25(\mathrm{OH}) \mathrm{D}$ in the carcinogenesis pathway of colorectal, breast, and prostate cancers. Solid-colored bars represent consistent evidence for protection against cancer, white bars represent no evidence, and hashed bars represent inconsistent evidence for the association between $25(\mathrm{OH}) \mathrm{D}$ and the indicated endpoints of pre-cancerous lesions and cancer incidence, progression, or mortality. 
In summary, after more than two decades of research into the association of vitamin $\mathrm{D}$ and cancer, results of association studies between $25(\mathrm{OH}) \mathrm{D}$ and colorectal, breast, and prostate cancer have indicated consistent inverse relationships for colorectal adenoma incidence, colorectal cancer incidence and mortality, and for breast cancer progression and/or mortality. In contrast, randomized, double-blind clinical trials conducted to date have failed to support these findings. Until the results of ongoing clinical trials are reported, it will be difficult to ascertain if vitamin D itself is related to a reduction in risk for some cancer endpoints, or whether high concentrations of the vitamin $\mathrm{D}$ biomarker $25(\mathrm{OH}) \mathrm{D}$ serve as a marker for an overall beneficial risk factor profile ${ }^{59,118}$.

\section{Acknowledgement}

This work was supported by Public Health Service grants R01CA140285 and 5P30CA023074 at the University of Arizona.

\section{Competing Interests}

The authors have declared that no competing interest exists.

\section{References}

1. Siegel RL, Miller KD, Jemal A. Cancer statistics. CA: Cancer J Clin 2015; 65(1):5-29.

2. Siegel R, Ma J, Zou Z, Jemal A. Cancer statistics, 2014. CA: Cancer J Clin 2014; 64:9-29.

3. Leslie A, Carey FA, Pratt NR, et al. The colorectal adenoma-carcinoma sequence. Br J Surg 2002;89:845-65.

4. Heitman SJ, Ronksley PE, Hilsden RJ, et al. Prevalence of adenomas and colorectal cancer in average risk individuals: a systematic review and meta-analysis. Clin Gastroenterol H 2009;7:1272-8.

5. Winawer SJ, Zauber AG, Fletcher RH, et al. Guidelines for colonoscopy surveillance after polypectomy: a consensus update by the US Multi-Society Task Force on Colorectal Cancer and the American Cancer Society. CA: Cancer J Clin 2006;56:143-596.

6. Yin L, Grandi N, Raum E, et al. Meta-analysis: Serum vitamin D and colorectal adenoma risk. Prev Med 2011;53(1-2):10-6.

7. Wei MY, Garland CF, Gorham ED, et al. Vitamin D and prevention of colorectal adenoma: a meta-analysis. Cancer Epidemiol Biomarkers Prev 2008;17:2958-69.

8. Jacobs ET, Hibler EA, Lance $\mathrm{P}$, et al. Association between circulating concentrations of $25(\mathrm{OH}) \mathrm{D}$ and colorectal adenoma: a pooled analysis. Int J Cancer 2013;133:2980-8.

9. Lao VV, Grady WM. Epigenetics and colorectal cancer. Nat Rev Gastroenterol Hepatol 2011 Oct 18;8(12):686-700

10. Horváth HC, Lakatos P, Kósa JP, et al. The candidate oncogene CYP24A1: A potential biomarker for colorectal tumorigenesis. J Histochem Cytochem 2010;58:277-85.

11. Matusiak D, Benya RV. CYP27A1 and CYP24 expression as a function of malignant transformation in the colon. J Histochem Cytochem 2007;55:1257-64.

12. Barry EL, Rees JR, Peacock JL et al Genetic variants in CYP2R1, CYP24A1, and VDR modify the efficacy of vitamin D3 supplementation for increasing serum 25-hydroxyvitamin D levels in a randomized controlled trial. J Clin Endocrinol Metab 2014 Oct; 99(10):E2133-7.

13. Ma Y, Zhang P, Wang F, et al. Association between vitamin D and risk of colorectal cancer: a systematic review of prospective studies. J Clin Oncol 2011 Oct 1;29(28):3775-82.

14. Gandini S, Boniol M, Haukka J, et al. Meta-analysis of observational studies of serum 25-hydroxyvitamin D levels and colorectal, breast and prostate cancer and colorectal adenoma. Int J Cancer 2011;128:1414-24

15. Touvier M, Chan DS, Lau R, et al. Meta-analyses of vitamin D intake, 25-hydroxyvitamin D status, vitamin D receptor polymorphisms, and colorectal cancer risk. Cancer Epidemiol Biomarkers Prev 2011;20:1003-16.
16. Lee JE, Li H, Chan AT, et al. Circulating levels of vitamin D and colon and rectal cancer: the Physicians' Health Study and a meta-analysis of prospective studies. Cancer Prev Res 2011;4:735-43.

17. Tangrea J, Helzlsouer $\mathrm{K}$, Pietinen $\mathrm{P}$, et al. Serum levels of vitamin D metabolites and the subsequent risk of colon and rectal cancer in Finnish men. Cancer Causes Control 1997;8:615-25.

18. Otani T, Iwasaki M, Sasazuki S, et al. Plasma vitamin D and risk of colorectal cancer: the Japan Public Health Center-Based Prospective Study. Br J Cancer 2007;97:446-51.19.

19. Jenab M, Bueno-de-Mesquita HB, Ferrari $\mathrm{P}$, et al. Association between pre-diagnostic circulating vitamin $\mathrm{D}$ concentration and risk of colorectal cancer in European populations:a nested case-control study. BMJ 2010 Jan 21;340:b5500.20.

20. Weinstein SJ, Purdue MP, Smith-Warner SA, et al. Serum 25-hydroxyvitamin $\mathrm{D}$, vitamin D binding protein and risk of colorectal cancer in the Prostate, Lung, Colorectal and Ovarian Cancer Screening Trial. Int J Cancer 2015 Mar 15;136(6):E654-64.

21. Feskanich D, Ma J, Fuchs CS, et al. Plasma vitamin D metabolites and risk of colorectal cancer in women. Cancer Epidemiol Biomarkers Prev 2004;13:1502-8

22. Wactawski-Wende J, Kotchen JM, Anderson GL, et al. Calcium plus vitamin D supplementation and the risk of colorectal cancer. New Engl J Med 2006;354:684-96

23. Weinstein SJ, Yu K, Horst RL, et al. Serum 25-hydroxyvitamin D and risks of colon and rectal cancer in Finnish men. Am J Epidemiol 2011;173:499-508.

24. Wong $\mathrm{YY}, \mathrm{Hyde} \mathrm{Z}, \mathrm{McCaul} \mathrm{KA}$, et al. In older men, lower plasma 25-hydroxyvitamin $\mathrm{D}$ is associated with reduced incidence of prostate, but not colorectal or lung cancer. PloS One 2014;9:e99954.

25. Trivedi DP, Doll R, Khaw KT. Effect of four monthly oral vitamin D3 (cholecalciferol) supplementation on fractures and mortality in men and women living in the community:7 randomised double blind controlled trial. BMJ 2003 Mar 1;326(7387):469.

26. Lappe JM, Travers-Gustafson D, Davies KM, et al. Vitamin D and calcium supplementation reduces cancer risk: results of a randomized trial. Am J Clin Nutr 2007;85:1586-91.

27. Manson JE, Bassuk SS, Lee IM, et al. The VITamin D and OmegA-3 TriaL (VITAL): rationale and design of a large randomized controlled trial of vitamin D and marine omega-3 fatty acid supplements for the primary prevention of cancer and cardiovascular disease. Contemp Clin Trials 2012;33:159-71

28. Mezawa H, Sugiura T, Watanabe M, et al. Serum vitamin D levels and survival of patients with colorectal cancer: post-hoc analysis of a prospective cohort study. BMC Cancer 2010;10:347.

29. Ng K, Sargent DJ, Goldberg RM, et al. Vitamin D status in patients with stage IV colorectal cancer: findings from Intergroup trial N9741. J Clin Oncol 2011;29:1599-606.

30. Freedman DM, Looker AC, Abnet CC, et al. Serum 25-hydroxyvitamin D and cancer mortality in the NHANES III study (1988-2006). Cancer Res 2010;70:8587-9731.

31. Fedirko V, Riboli E, Tjønneland A, et al. Prediagnostic 25-hydroxyvitamin D, VDR and CASR polymorphisms, and survival in patients with colorectal cancer in western European populations. Cancer Epidemiol Biomarkers Prev 2012;21:582-93.

32. Tretli S, Schwartz GG, Torjesen PA, et al. Serum levels of 25-hydroxyvitamin D and survival in Norwegian patients with cancer of breast, colon, lung, and lymphoma: a population-based study. Cancer Causes Control 2012;23:363-70.

33. Zgaga L, Theodoratou E, Farrington SM, et al. Plasma vitamin D concentration influences survival outcome after a diagnosis of colorectal cancer. J Clin Oncol 2014:32:2430-9.

34. Wesa KM, Segal NH, Cronin AM, et al. Serum 25- Hydroxy Vitamin D and Survival in Advanced Colorectal Cancer: A Retrospective Analysis. Nut Cancer 2015:1-7.

35. Ng K, Meyerhardt JA, Wu K, et al. Circulating 25-hydroxyvitamin d levels and survival in patients with colorectal cancer. J Clin Oncol 2008;26:2984-91.

36. Maalmi H, Ordonez-Mena JM, Schottker B, et al. Serum 25-hydroxyvitamin D levels and survival in colorectal and breast cancer patients: systematic review and meta-analysis of prospective cohort studies. Eur J Cancer 2014:50:1510-21.

37. Wang B, Jing Z, Li C, et al. Blood 25-hydroxyvitamin D levels and overall mortality in patients with colorectal cancer: a dose-response meta-analysis. Eur J Cancer 2014:50:2173-5.

38. Li M, Chen P, Li J, et al. Review: the impacts of circulating 25-hydroxyvitamin D levels on cancer patient outcomes: a systematic review and meta-analysis. J Clin Endocrinol Metab 2014;99:2327-36.

39. Rohan TE, Negassa A, Chlebowski RT, et al. A randomized controlled trial of calcium plus vitamin D supplementation and risk of benign proliferative breast disease. Breast Cancer Res Treat 2009;116:339-50.

40. Yin L, Grandi N, Raum E, et al. Meta-analysis: serum vitamin D and breast cancer risk. Eur J Cancer 2010;46:2196-205.

41. Chen $\mathrm{P}, \mathrm{Li} \mathrm{M}, \mathrm{Gu} X$, et al. Higher blood 25(OH)D level may reduce the breast cancer risk: evidence from a Chinese population based case-control study and meta-analysis of the observational studies. PloS One 2013;8:e49312

42. Kim Y, Je Y. Vitamin D intake, blood 25(OH)D levels, and breast cancer risk or mortality: a meta-analysis. Br J Cancer 2014;110:2772-84

43. Jacobs ET, Thomson CA, Flatt SW, et al. Vitamin D and breast cancer recurrence in the Women's Healthy Eating and Living (WHEL) Study. Am J Clin Nutr 2011;93:108-17. 
44. Engel P, Fagherazzi G, Boutten A, et al. Serum $25(\mathrm{OH})$ vitamin D and risk of breast cancer: a nested case-control study from the French E3N cohort. Cancer Epidemiol Biomarkers Prev 2010;19:2341-50.

45. Eliassen AH, Spiegelman D, Hollis BW, et al. Plasma 25-hydroxyvitamin D and risk of breast cancer in the Nurses' Health Study II. Breast Cancer Res 2011;13:R50.

46. Yao S, Sucheston LE, Millen AE, et al. Pretreatment serum concentrations of 25-hydroxyvitamin D and breast cancer prognostic characteristics: a case-control and a case-series study. PloS One 2011;6:e17251.

47. Neuhouser ML, Manson JE, Millen A, et al. The influence of health and lifestyle characteristics on the relation of serum 25-hydroxyvitamin D with risk of colorectal and breast cancer in postmenopausal women. Am J Epidemiol 2012;175:673-84.

48. Amir E, Cecchini RS, Ganz PA, et al. 25-Hydroxy vitamin-D, obesity, and associated variables as predictors of breast cancer risk and tamoxifen benefit in NSABP-P1. Breast Cancer Res Treat 2012;133:1077-88.

49. Peppone LJ, Rickles AS, Janelsins MC, et al. The association between breast cancer prognostic indicators and serum 25-OH vitamin D levels. Ann Surg Oncol 2012;19:2590-9.

50. Bilinski K, Boyages J. Association between 25-hydroxyvitamin D concentration and breast cancer risk in an Australian population: an observational case-control study. Breast Cancer Res Treat 2013;137:599-607.

51. Kühn T, Kaaks R, Becker S, et al. Plasma 25-hydroxyvitamin D and the risk of breast cancer in the European prospective investigation into cancer and nutrition: a nested case-control study. Int J Cancer 2013;133:1689-700.

52. Mohr SB, Gorham ED, Alcaraz JE, et al. Serum 25- hydroxyvitamin D and breast cancer in the military: a case-control study utilizing pre-diagnostic serum. Cancer Causes Control 2013:24:495-504.

53. Ordóñez-Mena JM, Schöttker B, Haug U, et al. Serum 25-hydroxyvitamin d and cancer risk in older adults: results from a large German prospective cohort study. Cancer Epidemiol Biomarkers Prev 2013;22:905-16.

54. Yousef FM, Jacobs ET, Kang PT, et al. Vitamin D status and breast cancer in Saudi Arabian women: case-control study. Am J Clin Nutr 2013;98:105-10.

55. Skaaby T, Husemoen LL, Thuesen BH, et al. Prospective population-based study of the association between serum 25-hydroxyvitamin-D levels and the incidence of specific types of cancer. Cancer Epidemiol Biomarkers Prev 2014;23:1220-9.

56. Wang J, Eliassen AH, Spiegelman D, et al. Plasma free 25-hydroxyvitamin D, vitamin D binding protein, and risk of breast cancer in the Nurses' Health Study II. Cancer Causes Control 2014;25:819-27.

57. Scarmo S, Afanasyeva $Y$, Lenner $P$, et al. Circulating levels of 25-hydroxyvitamin D and risk of breast cancer: a nested case-control study. Breast Cancer Res 2013;15:R15.

58. Chlebowski RT. Vitamin D and breast cancer: interpreting current evidence. Breast Cancer Res 2011;13:217.

59. Jacobs ET, Martinez ME, Jurutka PW. Vitamin D: marker or mechanism of action? Cancer Epidemiol Biomarkers Prev 2011; 20:585-90.

60. Chlebowski RT. Vitamin D and breast cancer incidence and outcome. Anticancer Agents Med Chem 2013;13:98-106.

61. Chlebowski RT, Johnson KC, Kooperberg C, et al. Calcium plus vitamin D supplementation and the risk of breast cancer. J Natl Cancer Inst 2008;100:1581-91.

62. Vrieling A, Seibold P, Johnson TS, et al. Circulating 25-hydroxyvitamin D and postmenopausal breast cancer survival: Influence of tumor characteristics and lifestyle factors? Int J Cancer 2014:134:2972-83.

63. Palmieri C, MacGregor T, Girgis S, et al. Serum 25-hydroxyvitamin D levels in early and advanced breast cancer. J Clin Path 2006;59:1334-6

64. Goodwin PI, Ennis M, Pritchard KI, et al. Prognostic effects of 25-hydroxyvitamin D levels in early breast cancer. J Clin Oncol 2009;27:3757-63

65. Vrieling A, Hein R, Abbas S, et al. Serum 25-hydroxyvitamin D and postmenopausal breast cancer survival: a prospective patient cohort study. Breast Cancer Res 2011;13:R74.

66. Hatse S, Lambrechts D, Verstuyf A, et al. Vitamin D status at breast cancer diagnosis: correlation with tumor characteristics, disease outcome, and genetic determinants of vitamin D insufficiency. Carcinogenesis 2012;33:1319-26.

67. Zeichner SB, Koru-Sengul T, Shah N, et al. Improved clinical outcomes associated with vitamin $\mathrm{D}$ supplementation during adjuvant chemotherapy in patients with HER2+ nonmetastatic breast cancer. Clinical Breast Cancer 2015 Feb;15(1):e1-11.

68. Nesby-O'Dell S, Scanlon KS, Cogswell ME, et al. Hypovitaminosis D prevalence and determinants among African American and white women of reproductive age: Third National Health and Nutrition Examination Survey, 1988-1994. Am J Clin Nutr 2002;76:187-92.

69. Hanley DA, Davison KS. Vitamin D insufficiency in North America. J Nutr 2005;135:332-7.

70. Schwartz GG, Hulka BS. Is vitamin D deficiency a risk factor for prostate cancer? (Hypothesis). Anticancer Res 1990;10:1307-11.

71. Gee J, Bailey H, Kim K, et al. Phase II open label, multi-center clinical trial of modulation of intermediate endpoint biomarkers by 1alpha-hydroxyvitamin D2 in patients with clinically localized prostate cancer and high grade PIN. Prostate 2013;73:970-8.

72. Braun MM, Helzlsouer KJ, Hollis BW, et al. Prostate Cancer and prediagnostic levels of serum vitamin D metabolites (Maryland, United States). Cancer Causes Control 1995;6:235-9.
73. Gann $\mathrm{PH}$, Ma J, Hennekens $\mathrm{CH}$, et al. Circulating vitamin D metabolites in relation to subsequent development of prostate cancer. Cancer Epidemiology Biomarkers Prev 1996;5:121-6.

74. Nomura AM, Stemmermann GN, Lee J, et al. Serum vitamin D metabolite levels and the subsequent development of prostate cancer (Hawaii, United States). Cancer Causes Control 1998;9:425-32.

75. Ahonen $\mathrm{MH}$, Tenkanen $\mathrm{L}$, Teppo $\mathrm{L}$, et al. Prostate cancer risk and prediagnostic serum 25-hydroxyvitamin D levels (Finland). Cancer Causes Control 2000;11:847-52.

76. Tuohimaa $\mathrm{P}$, Tenkanen $\mathrm{L}$, Ahonen $\mathrm{M}$, et al. Both high and low levels of blood vitamin D are associated with a higher prostate cancer risk: a longitudinal, nested case-control study in the Nordic countries. Int J Cancer 2004;108:104-8.

77. Jacobs ET, Giuliano AR, Martinez ME, et al. Plasma levels of 25-hydroxyvitamin D, 1,25-dihydroxyvitamin D and the risk of prostate cancer. J Ster Biochem Mol Biol 2004;89-90:533-7.

78. Platz EA, Leitzmann MF, Hollis BW, et al. Plasma 1,25-dihydroxy- and 25-hydroxyvitamin D and subsequent risk of prostate cancer. Cancer Causes Control 2004;15:255-65.

79. Baron JA, Beach M, Wallace K, et al. Risk of prostate cancer in a randomized clinical trial of calcium supplementation. Cancer Epidemiol Biomarkers Prev 2005;14:586-9.

80. Tuohimaa $\mathrm{P}$, Tenkanen $\mathrm{L}$, Syvälä $\mathrm{H}$, et al. Interaction of factors related to the metabolic syndrome and vitamin D on risk of prostate cancer. Cancer Epidemiol Biomarkers Prev 2007;16:302-7.

81. Faupel-Badger JM, Diaw L, Albanes D, et al. Lack of association between serum levels of 25-hydroxyvitamin D and the subsequent risk of prostate cancer in Finnish men. Cancer Epidemiol Biomarkers Prev 2007;16:2784-6.

82. Li H, Stampfer MJ, Hollis JB, et al. A prospective study of plasma vitamin D metabolites, vitamin D receptor polymorphisms, and prostate cancer. PLoS Medicine 2007;4:e103.

83. Mikhak B, Hunter DJ, Spiegelman D, et al. Vitamin D receptor (VDR) gene polymorphisms and haplotypes, interactions with plasma 25-hydroxyvitamin $\mathrm{D}$ and 1,25-dihydroxyvitamin D, and prostate cancer risk. The Prostate 2007;67:911-23

84. Ahn J, Peters U, Albanes D, et al. Serum vitamin D concentration and prostate cancer risk: a nested case-control study. J Natl Cancer Inst 2008;100:796-80481.

85. Travis RC, Crowe FL, Allen NE, et al. Serum vitamin D and risk of prostate cancer in a case-control analysis nested within the European Prospective Investigation into Cancer and Nutrition (EPIC). Am J Epidemiol 2009;169:1223-32.

86. Park SY, Cooney RV, Wilkens LR, et al. Plasma 25-hydroxyvitamin D and prostate cancer risk: the multiethnic cohort. Eur J Cancer 2010;46:932-6.

87. Barnett CM, Nielson CM, Shannon J, et al. Serum 25-OH vitamin D levels and risk of developing prostate cancer in older men. Cancer Causes Control 2010;21:1297-303.

88. Albanes D, Mondul AM, Yu K, et al. Serum 25-hydroxy vitamin D and prostate cancer risk in a large nested case-control study. Cancer Epidemiol Biomarkers Prev 2011;20:1850-60.

89. Gilbert R, Metcalfe C, Fraser WD, et al. Associations of circulating 25-hydroxyvitamin $\mathrm{D}$ with prostate cancer diagnosis, stage and grade. Int J Cancer 2012;131:1187-96.

90. Brandstedt J, Almquist M, Manjer J, et al. Vitamin D, PTH, and calcium and the risk of prostate cancer: a prospective nested case-control study. Cancer Causes Control 2012;23:1377-85.

91. Shui IM, Mucci LA, Kraft P, et al. Vitamin D-related genetic variation, plasma vitamin $\mathrm{D}$, and risk of lethal prostate cancer: a prospective nested case-control study. J Natl Cancer Inst 2012;104:690-9.

92. Meyer HE, Robsahm TE, Bjorge T, et al. Vitamin D, season, and risk of prostate cancer: a nested case-control study within Norwegian health studies. Am J Clin Nutr 2013;97:147-54

93. Kristal AR, Till C, Song $X$, et al. Plasma vitamin $D$ and prostate cancer risk: results from the Selenium and Vitamin E Cancer Prevention Trial. Cancer Epidemiol Biomarkers Prev 2014;23:1494-504.

94. Schenk JM, Till CA, Tangen CM, et al. Serum 25- hydroxyvitamin d concentrations and risk of prostate cancer: results from the Prostate Cancer Prevention Trial. Cancer Epidemiol Biomarkers Prev 2014;23:1484-93.

95. Shui IM, Mondul AM, Lindström S, et al. Circulating vitamin D, vitamin D-related genetic variation, and risk of fatal prostate cancer in the National Cancer Institute Breast and Prostate Cancer Cohort Consortium. Cancer. 2015 Mar 2; [Epub ahead of print].

96. $\mathrm{Xu} Y$, Shao $\mathrm{X}$, Yao $\mathrm{Y}$, et al Positive association between circulating 25-hydroxyvitamin D levels and prostate cancer risk: new findings from an updated meta-analysis. J Cancer Res Clin Oncol 2014;140:1465-77.

97. Schwartz GG. Vitamin D in blood and risk of prostate cancer: lessons from the Selenium and Vitamin E Cancer Prevention Trial and the Prostate Cancer Prevention Trial. Cancer Epidemiol Biomarkers Prev 2014;23:1447-9.

98. Marshall DT, Savage SJ, Garrett-Mayer E, et al. Vitamin D3 supplementation at 4000 international units per day for one year results in a decrease of positive cores at repeat biopsy in subjects with low-risk prostate cancer under active surveillance. J Clin Endocrinol Metab 2012;97:2315-24.

99. Fang F, Kasperzyk JL, Shui I, et al. Prediagnostic plasma vitamin D metabolites and mortality among patients with prostate cancer. PloS One 2011;6:e18625 
100. Tretli S, Hernes E, Berg JP, et al. Association between serum 25(OH)D and death from prostate cancer. Br J Cancer 2009;100:450-4.

101. Freedman DM, Looker AC, Chang SC, et al. Prospective study of serum vitamin D and cancer mortality in the United States. Journal of the National Cancer Institute 2007;99:1594-602.

102. Holt SK, Kolb S, Fu R, et al. Circulating levels of 25-hydroxyvitamin D and prostate cancer prognosis. Cancer Epidemiol 2013;37:666-70.

103. Royston P, Altman DG, Sauerbrei W. Dichotomizing continuous predictors in multiple regression: a bad idea. Stat Med 2006;25:127-41.

104. Peehl DM, Skowronski RJ, Leung GK, et al. Antiproliferative effects of 1,25-dihydroxyvitamin D3 on primary cultures of human prostatic cells. Cancer Res 1994;54:805-10.

105. Frampton RJ, Omond SA, Eisman JA. Inhibition of human cancer cell growth by 1,25- dihydroxyvitamin D3 metabolites. Cancer Res 1983;43:4443-7.

106. Giuliano AR, Franceschi RT, Wood RJ. Characterization of the vitamin D receptor from the Caco-2 human colon carcinoma cell line: effect of cellular differentiation. Arch Biochem Biophys 1991;285:261-9.

107. Shabahang M, Buras RR, Davoodi F, et al. 1,25-Dihydroxyvitamin D3 receptor as a marker of human colon carcinoma cell line differentiation and growth inhibition. Cancer Res 1993;53:3712-8.

108. Hollis BW. Assessment of circulating 25(OH)D and 1,25(OH)2D: emergence as clinically important diagnostic tools. Nutr Rev 2007;65:S87-90.

109. Bea JW, Jurutka PW, Hibler EA, et al. Concentrations of the vitamin D metabolite 1,25(OH)2D and odds of metabolic syndrome and its components. Metabolism 2015;64:447-59.

110. Feldman D, Krishnan AV, Swami S, et al. The role of vitamin D in reducing cancer risk and progression. Nat Rev Cancer 2014;14:342-57.

111. Cross HS, Bareis P, Hofer $\mathrm{H}$, et al. 25-Hydroxyvitamin $\mathrm{D}(3)-1$ alpha-hydroxylase and vitamin $\mathrm{D}$ receptor gene expression in human colonic mucosa is elevated during early cancerogenesis. Steroids 2001;66:287-92.

112. Bises G, Kállay E, Weiland T, et al. 25-hydroxyvitamin D3-1alpha-hydroxylase expression in normal and malignant human colon. J Histochem Cytochem 2004;52:985-9.

113. Jacobs ET, Van Pelt C, Forster RE, et al. CYP24A1 and CYP27B1 polymorphisms modulate vitamin D metabolism in colon cancer cells. Cancer Res 2013; 73:2563-73

114. Lin PH, Aronson W, Freedland SJ. Nutrition, dietary interventions and prostate cancer: the latest evidence. BMC Med 2015;13:3.

115. Song M, Garrett WS, Chan AT. Nutrients, foods, and colorectal cancer prevention. Gastroenterol 2015;148:1244-60 e16.

116. Quarles LD. Endocrine functions of bone in mineral metabolism regulation. J Clin Investigation 2008;118:3820-8.

117. Jacobs ET, Jurutka PW, Martinez ME, Alberts DS. Vitamin D, calcium, and colorectal neoplasia: new insights on mechanisms of action. Cancer Prev Res 2009;2:197-9.

118. Autier P, Boniol M, Pizot C, Mullie P. Vitamin D status and ill health: a systematic review. Lancet Diabetes Endocrinol 2014;2:76-89. 